\title{
ESTIMAÇÃO DA ÁREA FOLIAR DO ALGODOEIRO POR MEIO DE DIMENSÕES E MASSA DAS FOLHAS ${ }^{(1)}$
}

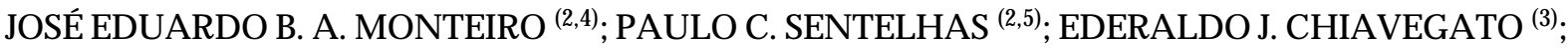 \\ CRISTIANE GUISELINI ${ }^{(2,5)}$; ALAILSON V.SANTIAGO ${ }^{(2,4)}$; ANGÉLICA PRELA $^{(2,4)}$
}

\begin{abstract}
RESUMO
O objetivo deste trabalho foi avaliar dois métodos de estimação da área foliar do algodoeiro, por meio de suas dimensões e massa seca das folhas. Foram utilizadas as cultivares IAC 23 e Coodetec 401. No método que utilizou dimensões, as folhas do algodoeiro foram agrupadas em novas, cordiformes e maduras. Para cada tipo de folha, de cada cultivar, foi determinado um fator de forma (FF) por meio de análise de regressão entre o produto do comprimento (C) pela largura (L) e a área das folhas. Avaliouse a correlação entre a área foliar estimada pelo fator FF e sua medida direta, utilizando-se dados independentes. Testou-se, ainda, um fator único para cada cultivar, independente do estádio da cultura e, também, um fator geral para as duas cultivares. No método que utilizou a massa seca, as folhas foram agrupadas em novas e maduras. Determinou-se o fator de massa seca (FM) por meio da análise de regressão entre a massa seca de folhas e respectivas áreas foliares. Em seguida, avaliou-se a correlação entre dados estimados por FM e dados medidos de forma direta, em nova amostra. O método das dimensões é viável para a estimação de área foliar do algodoeiro, por apresentar boa precisão e exatidão, com $\mathrm{r}^{2}$ entre 0,71 e 0,98 e com coeficiente angular da regressão entre 0,87 e 0,95. No entanto, pelo método da massa seca, observaram-se precisão e exatidão maiores, com $\mathrm{r}^{2}$ entre 0,94 e 0,98, e coeficiente angular da regressão entre 0,97 e 1,00, com a vantagem de ser menos trabalhoso.
\end{abstract}

Palavras-chave: Gossypium hirsutum, área foliar, estimação, índice de área foliar.

\section{ABSTRACT}

\section{COTTON LEAF AREA ESTIMATES BASED ON LEAF DIMENSIONS AND DRY MASS METHODS}

The objective of this study was to evaluate two different methods to estimate cotton leaf area (LA), based on leaf dimensions (length - L and width - W) and leaf dry mass (DM). Two cultivars, IAC 23 and Coodetec 401, were used. For leaf dimensions method, leaves were classified by age: young, heartshape, and mature. For each age class, a leaf shape factor (LSF) was obtained by simple linear regression between $L^{*} W$ and LA. For leaf dry mass method, leaves were classified in new and mature and a leaf dry mass factor (LDMF) was obtained by simple linear regression between DM and LA. LA estimates the two methods were compared to LA measured in an independent sample. Good accuracy was observed with both methods, but leaf dry mass method presented a better performance with $\mathrm{r}^{2}$ ranging from 0.94 to 0.98 and regression slopes between 0.97 and 1.00 , when regression line was forced thought the origin. In this case there is and advantage since leaf dry mass method is less time-consuming.

Key words: Gossypium hirsutum, cotton, leaf area index, leaf dimensions and dry mass.

$\left.{ }^{1}\right)$ Trabalho extraído de parte da dissertação de mestrado do primeiro autor, apresentada ao PPG em Física do Ambiente Agrícola/ESALQ/USP. Recebido para publicação em 16 de setembro de 2003 e aceito em 15 de setembro de 2004.

$\left({ }^{2}\right)$ Departamento de Ciências Exatas, Setor de Agrometeorologia, ESALQ/USP. Caixa Postal 9, 13418-900 Piracicaba (SP), Brasil. E-mail: eduardo@esalq.usp.br

$\left({ }^{3}\right)$ Departamento de Produção Vegetal, ESALQ/USP.

$\left({ }^{4}\right)$ Bolsista CAPES.

$\left({ }^{5}\right)$ Bolsista CNPq. 


\section{INTRODUÇÃO}

A análise quantitativa do crescimento é o primeiro passo na avaliação da produção vegetal e requer informações que podem ser obtidas sem a necessidade de equipamentos sofisticados. Para tanto, a quantidade de material contido na planta toda e em suas partes, ou seja, folhas, colmos, raízes e frutos e o tamanho do aparelho fotossintetizante, isto é, área foliar, devem ser conhecidos (Kvet et al., 1971).

O algodoeiro herbáceo (Gossypium hirsutum L. var. latifolium Hutch.) apresenta hábito de crescimento indeterminado, dois tipos de ramificação (monopodial e simpodial), dois tipos de folhas verdadeiras (dos ramos e dos frutos) e, pelo menos, duas gemas (axilar e extra-axilar) situadas na base de cada folha (MAUNEY, 1984). Essas características, juntamente com outros atributos morfológicos e fisiológicos, conferem a esta planta elevada plasticidade fenotípica, o que explica sua adaptação aos mais diversos ambientes.

Compreender o crescimento e o desenvolvimento do algodoeiro possibilita a implementação de estratégias de manejo para alto rendimento. $\mathrm{O}$ crescimento dessa espécie é muito dinâmico, variando em função do ambiente e do manejo. O estabelecimento de dossel apropriado para interceptar a radiação solar incidente é um dos componentes de produção que mais influencia a produtividade da cultura (OOSTERHUIS, 1999). Entre os vários fatores que influenciam na formação do dossel, encontram-se a cultivar, o clima, a fertilidade do solo e os sistemas de cultivo e de colheita (LACA-BUENDIA e FARIA, 1982).

A área foliar de uma planta depende do número e do tamanho das folhas, bem como do seu tempo de permanência na planta. Na avaliação do crescimento de comunidades vegetais emprega-se a área de terreno disponível às plantas como base para expressar a área foliar; assim, a área foliar por unidade de área de terreno define o índice de área foliar (IAF), que representa sua capacidade em explorar o espaço disponível.

A variação temporal da área foliar em uma cultura agrícola depende das condições edafoclimáticas, da cultivar e da densidade populacional, entre outros fatores. Geralmente, a área foliar aumenta até um máximo, decrescendo após algum tempo, sobretudo em função da senescência das folhas mais velhas. A fotossíntese, processo responsável pelo fornecimento da energia necessária ao crescimento e desenvolvimento da planta, depende do IAF. Assim, quanto mais rápido a cultura atingir o ótimo IAF e quanto mais tempo a área foliar permanecer ativa, maior será sua produtividade biológica.

A avaliação do desenvolvimento da área foliar do algodoeiro, assim como de outras espécies, pode ser usada para investigar sua adaptação ecológica a novos ambientes, sua competição com outras espécies, os efeitos de seu manejo e tratamentos culturais, a identificação da capacidade produtiva de seus diferentes genótipos e o efeito do ataque de doenças.

Com base no exposto, o objetivo do presente estudo foi avaliar dois métodos de estimação da área foliar de duas cultivares de algodoeiro.

\section{MATERIAL E MÉTODOS}

O trabalho foi realizado em área experimental da Fazenda Areão do Campus "Luiz de Queiroz", Universidade de São Paulo (ESALQ-USP), no município de Piracicaba, Estado de São Paulo, localizada nas coordenadas geográficas, latitude de $22^{\circ} 42^{\prime} \mathrm{S}$, longitude de $47^{\circ} 37^{\prime} \mathrm{W}$ e altitude de 546 metros.

Amostras de folhas de 12 parcelas idênticas das cultivares de algodoeiro, IAC 23 e Coodetec 401, foram retiradas de uma área experimental com 56 parcelas. Nessas parcelas, constituídas de quatro linhas de $5 \mathrm{~m}$ com espaçamento $0,90 \mathrm{~m}$ entre linhas e $10 \mathrm{~cm}$ entre plantas (111.111 plantas/hectare), considerou-se útil apenas as duas linhas centrais. A amostragem consistiu na retirada de duas plantas por parcela, uma de cada linha útil, das quais foram retiradas todas as folhas para a composição da amostra para a análise em laboratório.

\section{a) Método das dimensões}

O método baseou-se nas dimensões comprimento (C) e largura (L) das folhas. O comprimento foi definido como a distância entre o ponto de inserção do pecíolo no limbo foliar e a extremidade oposta da folha e a largura como a maior dimensão perpendicular ao eixo do comprimento, conforme a Figura 1.

As folhas do algodoeiro podem ser agrupadas em categorias distintas, de acordo com sua forma e tamanho. Visualmente, pode-se distinguir quanto à forma, três grupos (Figura 1) que, devido às suas características particulares, podem apresentar relações diferentes entre suas dimensões e respectivas áreas. Foram definidas como pertencentes a 1 . $^{\text {a }}$ classe (a) as folhas jovens, em expansão, que são bastante irregulares. 
(a)

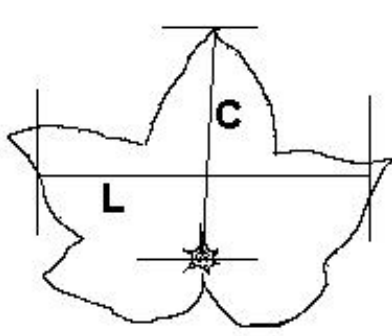

(b)

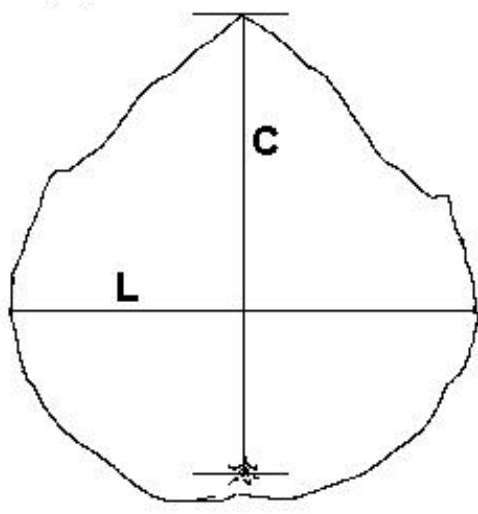

(c)

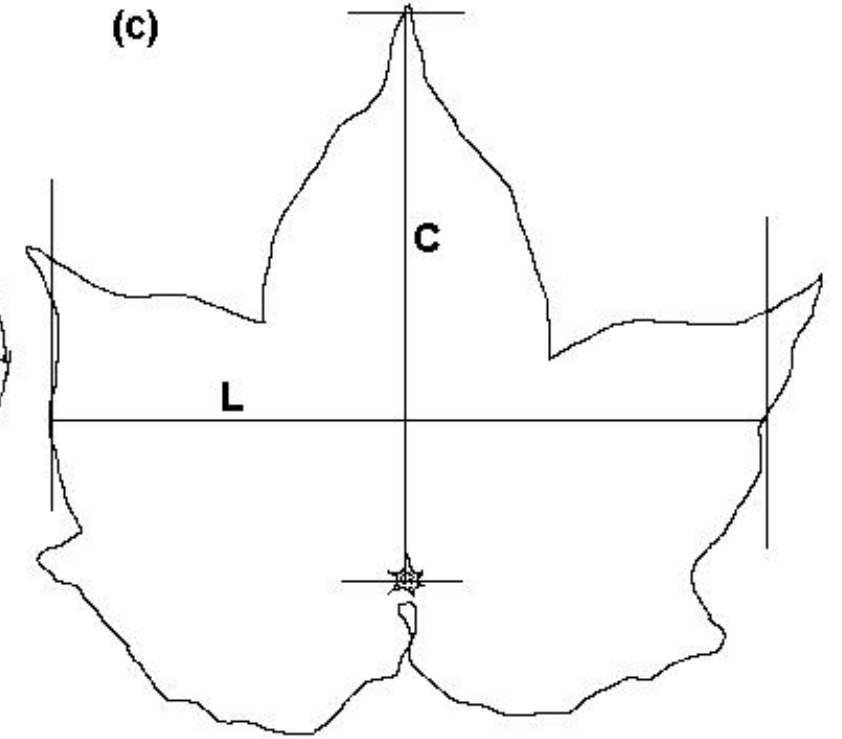

Figura 1. Contorno de imagens digitalizadas de folhas de algodoeiro jovem em expansão (a); folha cordiforme (b) e folha lobada expandida (c), com as indicações de seus respectivos comprimentos (C) e larguras (L).

As folhas cordiformes da $2 .^{a}$ classe (b), bem regulares, têm importância apenas nas fases iniciais de desenvolvimento da planta, já que são as primeiras a senescerem. As folhas da $3{ }^{a}$ classe (c), denominadas lobadas, são maiores e mais regulares que as folhas jovens. Estabeleceu-se como folhas jovens aquelas com área inferior a $45 \mathrm{~cm}^{2}$.

A área das folhas (Af) das três classes foi calculada como o produto das duas dimensões, comprimento (C) e largura (L), e um fator de forma "f", como a seguir:

$$
\text { Af }=f \times C \times L
$$

O fator de forma " $f$ " foi determinado pela análise de regressão simples entre a área de uma amostra de folhas e o produto de suas dimensões. Nesse caso, a reta ajustada ao conjunto de dados possui uma equação do tipo $\mathrm{Y}=\mathrm{bx}$, em que "b" corresponde ao fator " $\mathrm{f}$ ", determinado para as três classes foliares. A área das folhas amostradas foi determinada pela digitalização das respectivas imagens e posterior cálculo da área com o software Embrapa SIARC 3.0, de análise de imagens. A seguir, o fator de cada classe foi testado e validado, empregando-se a análise de regressão entre a área foliar estimada e a área foliar medida, em nova amostra de folhas, ou seja, com dados independentes.

Conforme o grau de desenvolvimento da planta, a proporção de classes de folhas varia em relação ao total. Assim, o fator "f" foi determinado levando-se em consideração, também, as proporções de cada classe de folhas aos 32, 65 e 95 dias após emergência da cultura (DAE), respectivamente nos estádios fenológicos R1 (primeiro botão floral), R4 (primeira maçã visível, final do florescimento) e R6 (frutificação plena) (STOLLER, s/ data). Assim, avaliouse o "f" para cada classe de folha, de cada cultivar. A seguir, foi avaliado um "f" para a planta toda, independente do tipo de folha, separando-se cada cultivar e os estádios fenológicos. Posteriormente, os dados gerados foram analisados em novas combinações, a fim de se verificar a possibilidade de simplificar o método de estimativa, e o quanto esse procedimento afetaria sua precisão. Para tanto, foi determinado e avaliado um "f" geral, independente do tipo de folha e estádio fenológico, para cada cultivar. Por fim, avaliou-se também, um "f" comum, único, independente do tipo de folha, do estádio fenológico e da cultivar.

\section{b) Método da massa seca}

A massa seca das folhas foi definida como a massa seca do limbo após remoção dos pecíolos rente a ele e medida em balança de precisão de $0,001 \mathrm{~g}$, após secagem em estufa ventilada a $50^{\circ} \mathrm{C}$, por 72 horas.

Devido às particularidades dos tipos de folhas, as razões de proporcionalidade entre sua massa seca das folhas e respectivas áreas poderiam variar, principalmente, entre as folhas jovens imaturas e as folhas maduras sem, no entanto, ser afetada pelas diferentes formas das folhas. Nesse caso, as análises foram feitas avaliando-se separadamente as classes que poderiam apresentar maior discrepância entre si, as folhas imaturas (a) e as expandidas (c). 
Assim, para as duas classes, a área das folhas (Af) foi calculada como o produto entre sua massa seca (ms) e um fator, denominado fator de massa "fm", como segue:

$$
\mathrm{Af}=\mathrm{fm} \times \mathrm{ms}
$$

$\mathrm{O}$ fator de massa "fm" foi determinado pela análise de regressão simples entre a área de uma amostra de folhas e suas respectivas massas secas. Assim, como no método anterior, a reta ajustada ao conjunto de dados possui uma equação do tipo $\mathrm{Y}=$ bx, em que "b" corresponde ao fator "fm", determinado para as duas classes foliares. A área das folhas amostradas também foi determinada com o uso do software Embrapa SIARC 3.0.

Em seguida, o "fm" de cada classe foi testado e validado como no método anterior. Nesse, porém, as amostras de folhas foram colhidas aos 95 dias após a emergência da cultura (DAE), estádio R6 (STOLLER, $\mathrm{s} /$ data). Nesse caso, a determinação do "fm" para a planta toda, nos dois estádios anteriores foi feita por meio da ponderação das proporções de folhas novas e de folhas maduras.

Portanto, primeiramente avaliou-se o "fm" para cada classe de folha, de cada cultivar. Na seqüência, foi avaliado um "fm" para a planta toda, independente do tipo de folha, mas ainda separando-se cada cultivar e os estádios fenológicos. Posteriormente, os dados gerados foram analisados em novas combinações, a fim de se avaliar a simplificação do método, determinando o "fm" geral, independente do tipo de folha e do estádio fenológico, para cada cultivar. Por fim, avaliou-se "fm" comum, único, independente do tipo de folha, do estádio fenológico ou da cultivar.

\section{RESULTADOS E DISCUSSÃO}

\section{a) Método das dimensões}

Nas análises de regressão da área foliar com o comprimento e a largura das folhas, realizadas separadamente, observaram-se menores graus de correlação (resultados não apresentados) do que aquela realizada com o produto das duas dimensões. PIREs et al. (1999), testando diferentes métodos para calcular a área foliar do morangueiro, por meio das dimensões das folhas, também obteve melhores resultados quando analisou comprimento e largura conjuntamente. Strik e Proctor (1985) também concluíram que a utilização do comprimento e da largura juntos estimou melhor a área dos folíolos de morangueiro.

Os coeficientes de determinação para as amostras de folhas podem ser observados na tabela 1. Todas as análises de regressão foram estatisticamente significativas, pelo teste $F$, para $p=$ 0,05 , com elevados coeficientes de correlação $\left(r^{2}\right)$.

Tabela 1. Análise de regressão entre o produto do comprimento pela largura $(\mathrm{C} x \mathrm{~L})$ das folhas de algodoeiro classificadas em três tipos e a área foliar medida de modo direto

\begin{tabular}{|c|c|c|c|c|c|c|}
\hline \multirow{2}{*}{$\begin{array}{l}\text { Cultivar } \\
\text { Parâmetros da análise }\end{array}$} & \multicolumn{3}{|c|}{ D 401} & \multicolumn{3}{|c|}{ IAC 23} \\
\hline & B & $\mathrm{r}^{2}$ & $\mathrm{~F}$ & $\mathrm{~b}$ & $\mathrm{r}^{2}$ & $\mathrm{~F}$ \\
\hline Folhas novas $\left(<45 \mathrm{~cm}^{2}\right)$ & 0,7695 & 0,810 & * & 0,7790 & 0,813 & * \\
\hline Folhas cordiformes & 0,8173 & 0,957 & * & 0,8221 & 0,948 & * \\
\hline Folhas lobadas $\left(=45 \mathrm{~cm}^{2}\right)$ & 0,8380 & 0,933 & * & 0,8615 & 0,921 & * \\
\hline
\end{tabular}

* Teste F significativo para $\mathrm{p}=0,05$.

Na figura 2, observam-se as análises de regressão entre a área foliar medida em uma amostra independente de folhas e a estimada a partir dos parâmetros apresentados na tabela 1 .

Foram obtidos elevados coeficientes de determinação e todas as análises foram significativas pelo teste $\mathrm{F}$, para $\mathrm{p}=0,05$. Mesmo com subestimativa de $5 \%$ a $13 \%$, o método das dimensões também apresentou resultados confiáveis ao ser utilizado para a estimação da área foliar em outras culturas, como em plantas forrageiras tipo braquiária, conforme descrito por SchiAvUZzo (1998), que obteve coeficiente de variação inferior a $10 \%$. Os resultados das avaliações das proporções de cada classe de folhas, conforme a cultivar e o grau de desenvolvimento das plantas são apresentados na tabela 2 .

Como apresentado na tabela 1 , notou-se em cada classe foliar um fator de forma característico. Os resultados da ponderação das classes de folhas para a determinação de um fator "f" único, para cada momento de avaliação, são apresentados na tabela 3 . 

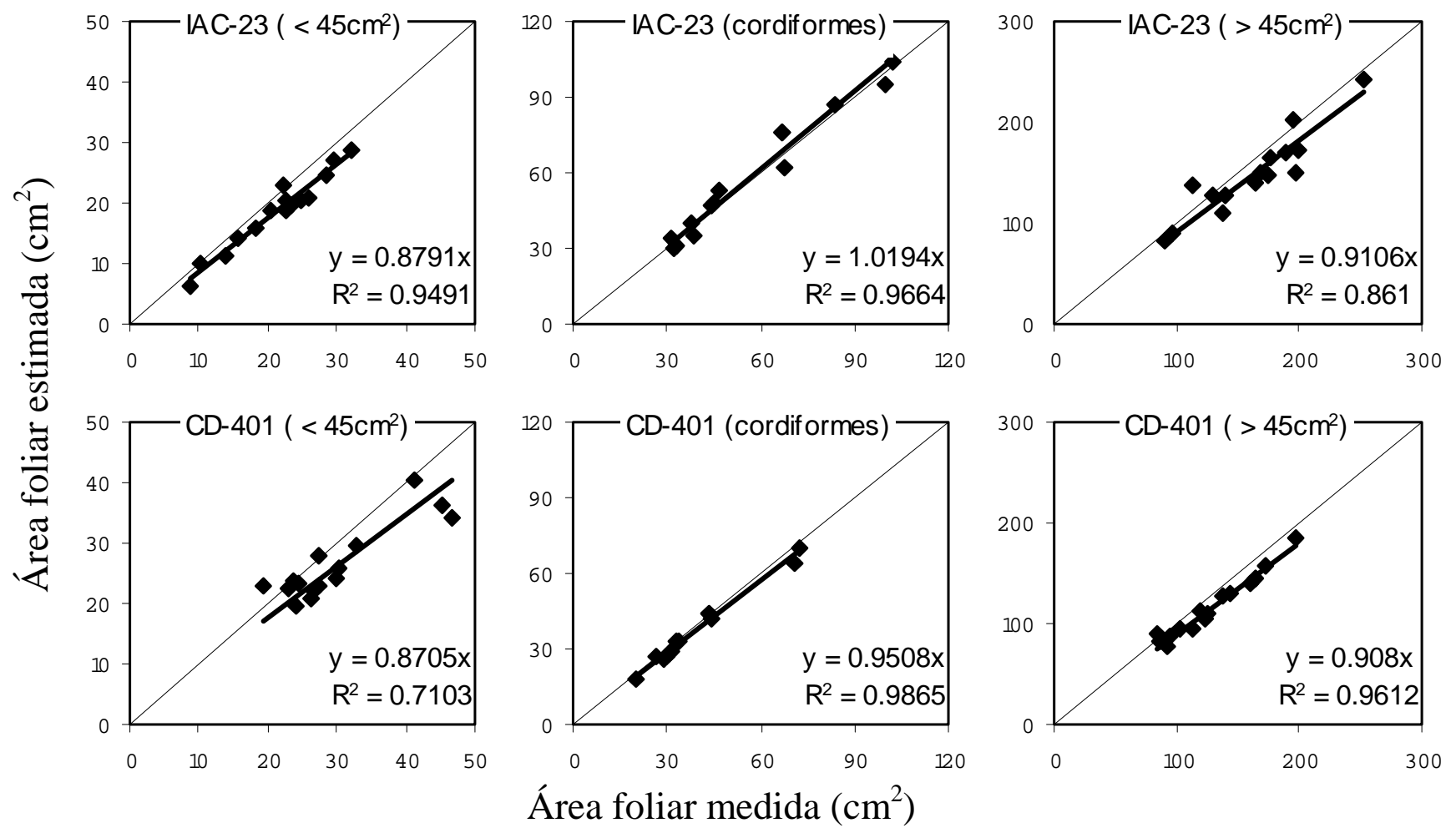

Figura 2. Relação entre a área foliar do algodoeiro estimada pelas dimensões das folhas classificadas em três tipos e a área foliar medida, nas cultivares IAC 23 e CD 401.

Tabela 2. Ponderação do número de folhas agrupadas nas três diferentes classes definidas aos 32,65 e 95 dias após emergência das duas cultivares de algodoeiro

\begin{tabular}{lcccccc}
\hline Cultivar & & CD 401 & & \multicolumn{3}{c}{ IAC 23 } \\
\cline { 2 - 3 } Dias após emergência & 32 & 65 & 95 & & 32 & 65 \\
\hline Total de folhas em 12 plantas & 158 & 627 & 832 & & 160 & 464 \\
Percentual de folhas novas $\left(<45 \mathrm{~cm}^{2}\right)$ & 44,9 & 27,4 & 30,6 & 35 & 23,3 & 21,8 \\
Percentual de folhas cordiformes & 22,8 & 5,7 & 0,0 & 22,5 & 7,8 & 0,0 \\
Percentual de folhas lobadas $\left(=45 \mathrm{~cm}^{2}\right)$ & 32,3 & 66,8 & 69,3 & 42,5 & 68,9 & 78,2 \\
\hline
\end{tabular}

Tabela 3. Análise de regressão entre o produto do comprimento pela largura $(\mathrm{CxL})$ das folhas e a área foliar medida, ponderando-se as classes de folhas aos 32, 65 e 95 dias após emergência

\begin{tabular}{|c|c|c|c|c|c|c|}
\hline \multirow{2}{*}{$\begin{array}{l}\text { Cultivar } \\
\text { Parâmetros da análise }\end{array}$} & \multicolumn{3}{|c|}{ CD 401} & \multicolumn{3}{|c|}{ IAC 23} \\
\hline & $\mathrm{b}$ & $\mathrm{r}^{2}$ & $\mathrm{~F}$ & $\mathrm{~b}$ & $\mathrm{r}^{2}$ & $\mathrm{~F}$ \\
\hline 32 dias após emergência & 0,8054 & 0,975 & * & 0,8389 & 0,954 & * \\
\hline 65 dias após emergência & 0,8301 & 0,976 & * & 0,8401 & 0,954 & * \\
\hline 95 dias após emergência & 0,8334 & 0,975 & $*$ & 0,8601 & 0,947 & * \\
\hline
\end{tabular}

* Teste F significativo para $\mathrm{p}=0,05$. 
Como pode ser observado na tabela 3 , de maneira geral, o fator de forma foi praticamente o mesmo aos 32, 65 e $95 \mathrm{DAE}$, ou seja, não variou segundo as épocas. Nesse caso, porém, houve aumento significativo do coeficiente de determinação, em relação àqueles verificados com o cálculo de cada classe de folhas feito separadamente. Logo, a dispersão do conjunto de dados foi menor e, conseqüentemente, a precisão da estimativa foi maior quando feita com o "f" ponderado.

Na prática, além da medida das folhas, a sua separação em classes dificultaria o trabalho de determinação da área foliar, já que a cada fase do ciclo, a planta emite novas folhas enquanto outras se desenvolvem. Como demonstrado nas análises apresentadas na figura 2 e tabela 3, é possível a utilização de um fator único para cada fase do ciclo, para todas as folhas da planta, sem que seja necessário classificá-las em cada determinação da área foliar e, sem que haja prejuízo para a precisão das estimativas, em razão da pequena variação entre os valores de "f" para cada classe.
Na figura 3, observa-se a relação entre a área foliar estimada e a medida (dados independentes), o que resultou em elevados coeficientes de determinação $\left(\mathrm{r}^{2}>0,96\right)$. Nesse caso, o " $\mathrm{f}$ " foi determinado pela média ponderada das quantidades de cada classe de folhas conforme as fases da cultura (30, 60 e 90 DAE).

Até aqui, verificou-se a viabilidade de redução do fator "f" de três classes de folhas para um único, ponderado em três épocas do ciclo. É possível simplificar mais o processo de estimação da área foliar, utilizando-se um fator " $f$ " único para qualquer época do ciclo. Nesse caso, há grande ganho de praticidade no processo, porém, com uma pequena diminuição na precisão da estimativa, como demonstrado na tabela 4 e figura 4 .

Como se constata na Tabela 4, a diferença entre os coeficientes estimados para as duas cultivares é pequena, o que evidencia que apesar da diferença de tamanho das folhas das cultivares, seu formato típico é praticamente o mesmo. Nesse caso, é viável a determinação de um coeficiente comum para as duas cultivares, como indicado na tabela 5 e na figura 5 .
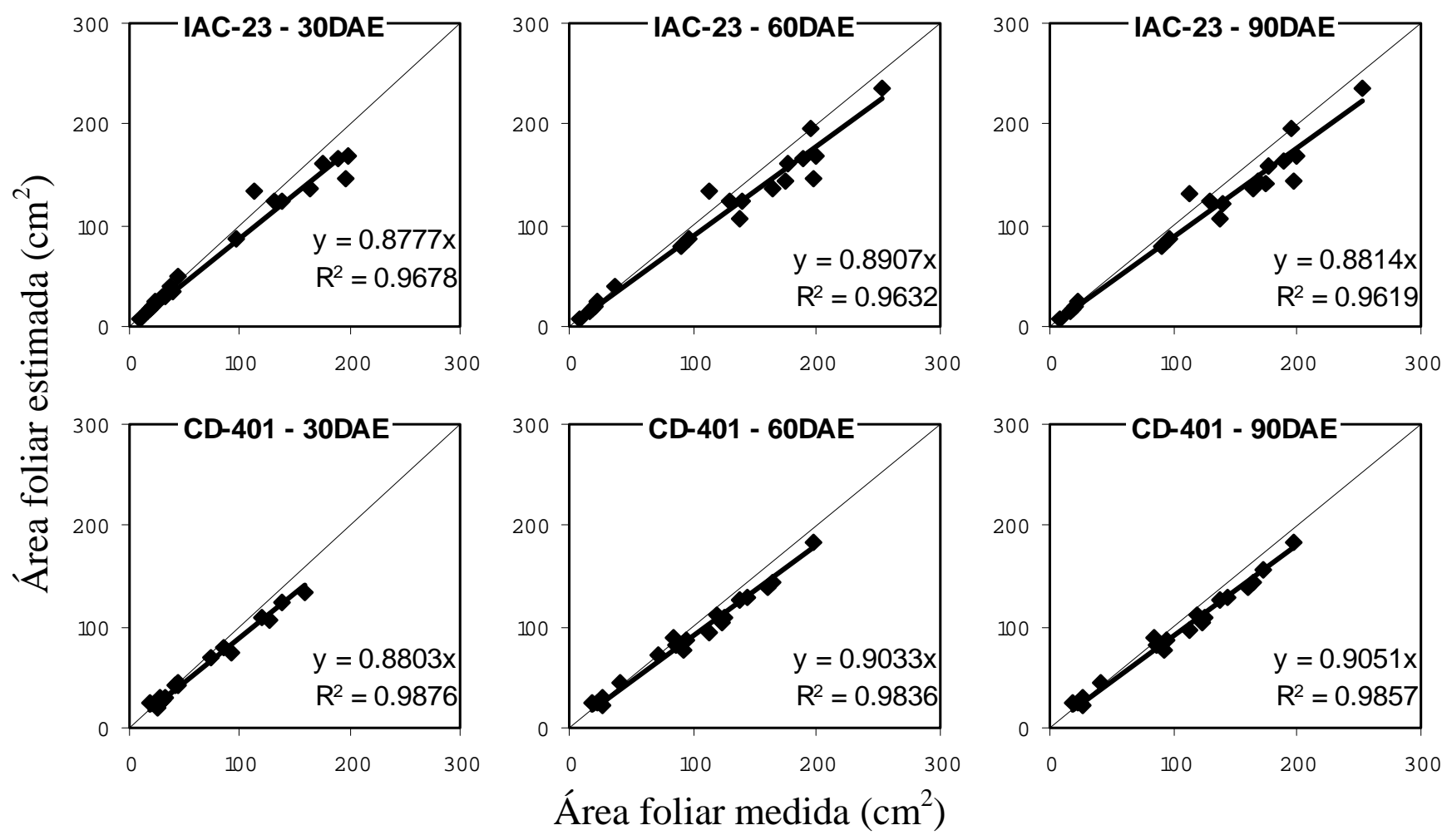

Figura 3. Relação entre área foliar estimada pelas dimensões das folhas e área foliar medida, avaliadas em três épocas do ciclo, nas cultivares IAC 23 e CD 401. 
Tabela 4. Análise de regressão entre o produto do comprimento pela largura $\left(C^{*} \mathrm{~L}\right)$ das folhas e a área foliar medida, considerando-se o valor médio da proporção das três classes foliares verificadas aos 32, 65 e 95 DAE

\begin{tabular}{|c|c|c|c|c|c|c|}
\hline \multirow{2}{*}{$\begin{array}{l}\text { Cultivar } \\
\text { Parâmetros da análise }\end{array}$} & \multicolumn{3}{|c|}{ CD 401} & \multicolumn{3}{|c|}{ IAC 23} \\
\hline & $b$ & $r^{2}$ & $\mathrm{~F}$ & B & $r^{2}$ & $\mathrm{~F}$ \\
\hline & 0,8267 & 0,9774 & $*$ & 0,8479 & 0,9527 & * \\
\hline
\end{tabular}

* Teste F significativo para $\mathrm{p}=0,05$.
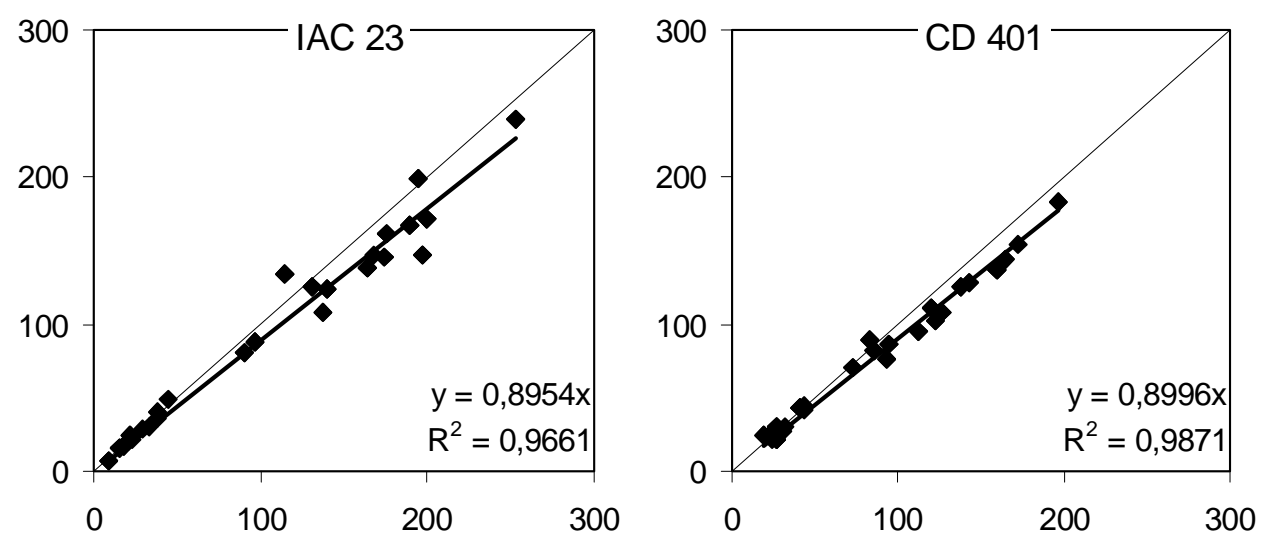

Figura 4. Relação entre a área foliar do algodoeiro estimada pelas dimensões das folhas e a área foliar medida, nas cultivares IAC 23 e CD 401, independente da fase da cultura.

Tabela 5. Análise de regressão entre o produto do comprimento pela largura (CxL) das folhas de algodoeiro e a área foliar medida em amostras mistas de folhas das cultivares IAC 23 e CD 401

\begin{tabular}{lccc}
\hline Cultivar & \multicolumn{3}{c}{ CD 401 e IAC 23 } \\
\cline { 2 - 3 } Parâmetros da análise & $\mathrm{b}$ & $\mathrm{r}^{2}$ & $\mathrm{~F}$ \\
\hline & 0,8396 & 0,9604 & $*$ \\
\hline
\end{tabular}

* Teste F significativo para $\mathrm{p}=0,05$.

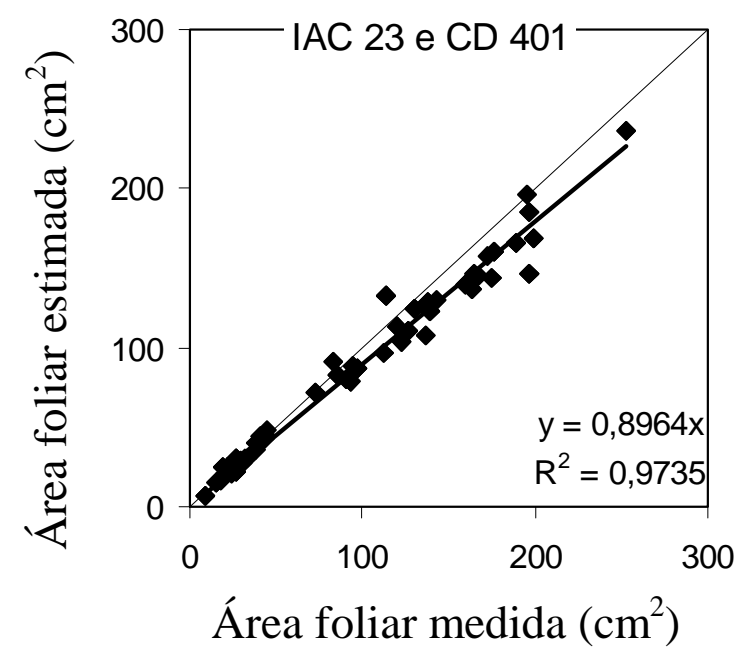

Figura 5. Relação entre a área foliar do algodoeiro estimada pelas dimensões das folhas e a área foliar medida. 
A maioria dos trabalhos disponíveis na literatura tem como objetivo principal a verificação de qual dimensão da folha ou do folíolo apresenta melhor correlação com a área da folha e da planta toda, sem dedicar muita atenção às diferenças de forma das folhas. Isso reflete a limitação prática inerente ao método que é, na verdade, a maior desvantagem do seu uso, que é a dificuldade de se realizar medidas em um número grande de folhas ou plantas. Por outro lado, a vantagem desse método é sua possibilidade de uso com um mínimo de recursos, além de ser utilizado como método não destrutivo. Em trabalhos futuros, é possível avaliar alternativas em métodos mais simples, que exijam menor número de medidas, levando em consideração a medida de apenas algumas folhas em posições predeterminadas, da altura da planta e/ou a largura da copa, ou mesmo, o número de folhas por planta.

\section{b) Método da massa seca}

A determinação do fator de massa "fm" para cada classe de folhas, por meio de análises de regressão com amostras de folhas, resultou nos coeficientes apresentados na tabela 6 . Como pode ser observado, todas as análises foram estatisticamente significativas, pelo teste $F$, para $p=0,01$, com elevados coeficientes de determinação $\left(\mathrm{r}^{2}\right)$.

Os fatores de massa determinados foram validados por meio da análise de uma nova amostra para cada tipo de folha e cada cultivar, conforme apresentado na Figura 6.

Nas estimativas da área foliar, com base em sua massa seca, os erros médios foram inferiores a 3\%, com maior exatidão do que no método das dimensões.

Tabela 6. Análise de regressão entre a massa seca das folhas classificadas como folhas lobadas novas $\left(<45 \mathrm{~cm}^{2}\right)$ e folhas lobadas expandidas $(=45 \mathrm{~cm} 2)$ e a área foliar medida

\begin{tabular}{|c|c|c|c|c|c|c|}
\hline \multirow{2}{*}{$\begin{array}{l}\text { Cultivar } \\
\text { Parâmetros da análise }\end{array}$} & \multicolumn{3}{|c|}{ CD 401} & \multicolumn{3}{|c|}{ IAC 23} \\
\hline & $\mathrm{b}$ & $\mathrm{r}^{2}$ & $\mathrm{~F}$ & B & $\mathrm{r}^{2}$ & $\mathrm{~F}$ \\
\hline Folhas novas $\left(<45 \mathrm{~cm}^{2}\right)$ & 155,79 & 0,932 & $* *$ & 165,45 & 0,911 & ** \\
\hline Folhas lobadas $\left(=45 \mathrm{~cm}^{2}\right)$ & 136,83 & 0,943 & $* *$ & 132,95 & 0,904 & ** \\
\hline
\end{tabular}

** Teste F significativo para $\mathrm{p}=0,01$.

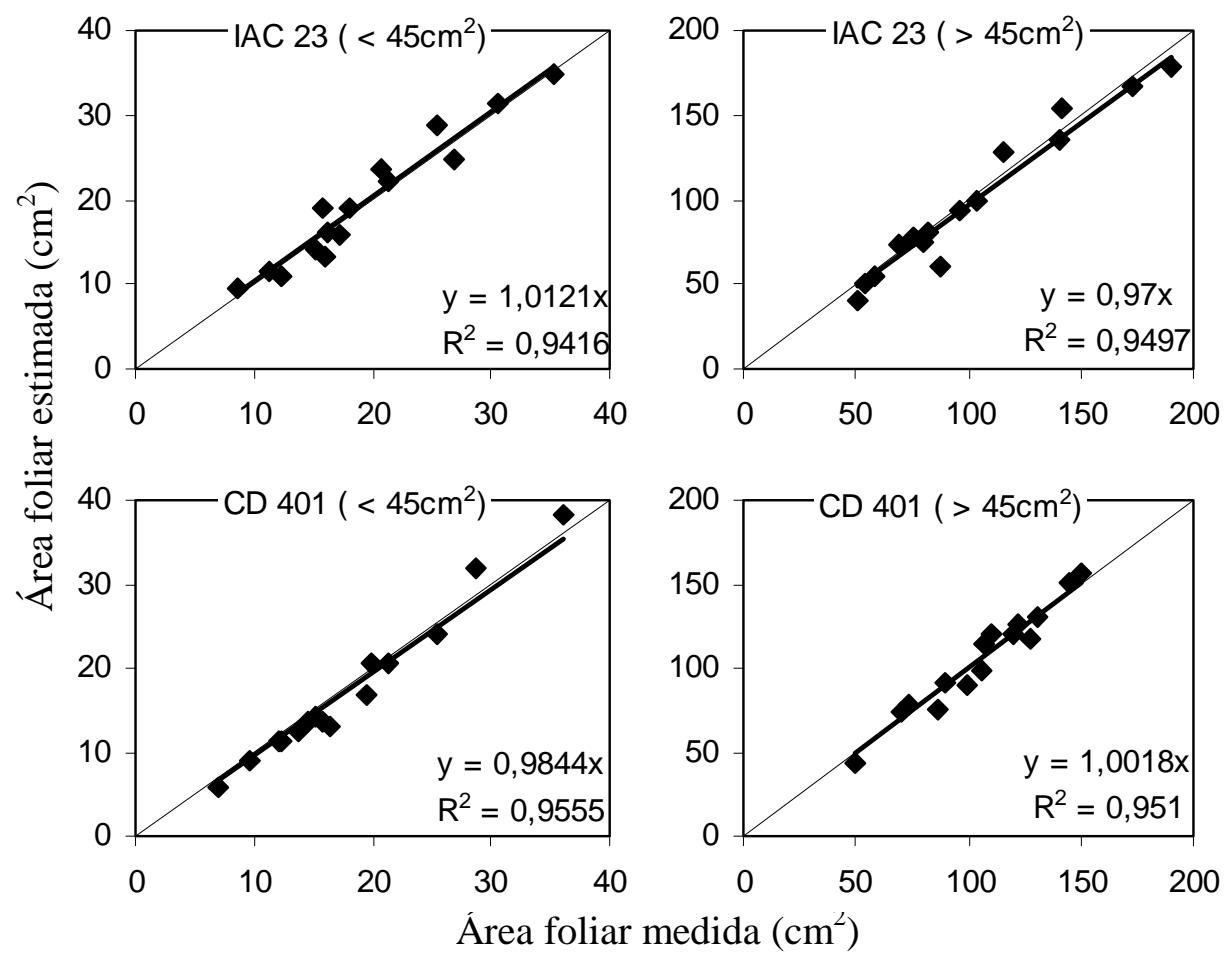

Figura 6. Relação entre a área foliar do algodoeiro estimada pelas massa seca das folhas e a área foliar medida, nas cultivares IAC 23 e CD 401, nas duas classes avaliadas. 
Uma maneira de simplificar o processo de estimação da área foliar de uma planta, seria utilizar um "fm" único, para que não fosse necessário separar as folhas de cada planta em classes conforme o tipo (Tabela 7).

Visto que os coeficientes obtidos para as duas cultivares pouco diferiram entre si, foi possível, ainda, utilizar apenas um fator de massa para ambas as cultivares. Na tabela 8 , verificam-se os resultados da análise de regressão feita a partir de uma amostra comum, com igual número de folhas das cultivares IAC 23 e CD 401.

Como se observa na figura 7 , a exatidão e a precisão das estimativas feitas a partir de um fator de massa "fm" único para ambas as cultivares praticamente não foram afetadas em relação às estimativas obtidas separadamente, para cada cultivar. Pelos resultados, verifica-se que a maneira mais fácil e prática de se estimar a área foliar do algodoeiro é pelo método das massas, não necessitando a medida de cada folha individualmente, como no caso do método das dimensões. No entanto, esse método requer a disponibilidade de uma balança, cuja precisão depende do número de folhas pesadas por vez e, também, de estufa de secagem.

Quando esses recursos não forem disponíveis, e se fizer necessária a medida da área foliar de plantas de algodoeiro, pode-se recorrer ao método das dimensões que, apesar de mais trabalhoso e de apresentar erros médios maiores, torna viável a estimação com o auxílio de apenas uma régua para a medida das folhas.

Tabela 7. Análise de regressão entre a massa seca das folhas e a área foliar medida das duas cultivares (IAC 23 e Coodetec 401)

\begin{tabular}{|c|c|c|c|c|c|c|}
\hline \multirow{2}{*}{$\begin{array}{l}\text { Cultivar } \\
\text { Parâmetros da análise }\end{array}$} & \multicolumn{3}{|c|}{ CD 401} & \multicolumn{3}{|c|}{ IAC 23} \\
\hline & $\mathrm{b}$ & r2 & $\mathrm{F}$ & $\mathrm{b}$ & r2 & $\mathrm{F}$ \\
\hline & 137,4 & 0.988 & $* *$ & 133,6 & 0.963 & $* *$ \\
\hline
\end{tabular}

** Teste F significativo para $\mathrm{p}=0,01$.

Tabela 8. Análise de regressão entre a massa seca das folhas e a área foliar medida para as duas cultivares juntas

\begin{tabular}{lccc}
\hline Cultivar & \multicolumn{3}{c}{ CD 401 e IAC 23 } \\
\cline { 2 - 4 } Parâmetros da análise & B & r2 & F \\
\hline & 135,6 & 0,975 & $* *$ \\
\hline
\end{tabular}

** Teste F significativo para $\mathrm{p}=0,01$.
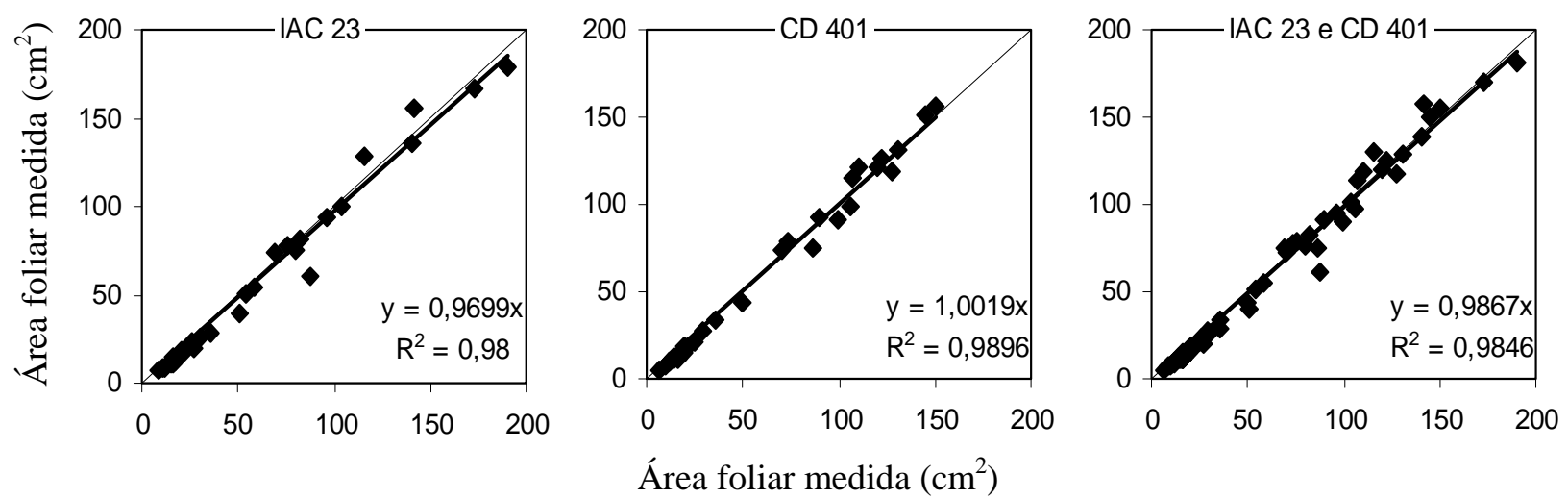

Figura 7. Análise de regressão entre a área foliar estimada e a área foliar medida, classificadas por cultivar (IAC 23 e CD 401), separada e conjuntamente. 


\section{CONCLUSÕES}

1. A área foliar do algodoeiro pode ser estimada com boa exatidão e excelente precisão a partir da medida das dimensões de suas folhas, com erros em torno de $10 \%$.

2. É possível estimar a área foliar do algodoeiro, com base na massa seca de suas folhas, com ótima exatidão e precisão e erros inferiores a $2 \%$;

3. A maneira mais fácil e prática de se determinar a área foliar do algodoeiro é pelo método das massas, não necessitando a medida de cada folha individualmente como no método das dimensões.

4. A área foliar da cultivar IAC 23 e da Coodetec 401 pode ser estimada por um fator de forma ou um fator de massa únicos para ambas, sem prejudicar a exatidão e precisão das estimativas.

\section{REFERÊNCIAS}

KVET, J.; ONDOK, J.P.; NECAS J.; JARVIS, P.G. Methods of growth analysis. In: SESTAK, Z.; CATSKY, J.; JARVIS, P.G. (Ed.). Plant Photosynthetic production: Manual of methods. The Hauge, W. Junk, N. V. Publishers, 1971. p.343-384.
LACA-BUENDIA, J.P.; FARIA, E.A. Manejo e tratos culturais do algodoeiro. Informe Agropecuário, Belo Horizonte, v.8, n.92, p.50-61, ago. 1982.

MAUNEY, J.R. Anatomy and morphology of cultivated cottons. In: KOHEL, R.J.; LEWIS, C.F. (Ed.). Cotton. Madison: American Society of Agronomy, 1984. p. 59-80.

OOSTERHUIS, H.J.W. Growth and development of cotton plant In: CIA, E.; FREIRE, E.C.; SANTOS, W.J. (Ed.). Cultura do algodoeiro. Piracicaba: Potafos, 1999. p.35-56.

STOLLER DO BRASIL LTDA. - Divisão Arbore. Guia de fases de desenvolvimento: Algodão. Cosmópolis, s/ data. 4p.

PIRES, R.C.M.; FOLEGATTI, M.V.; PASSOS, F.A. Estimativa da área foliar do morangueiro. Horticultura Brasileira, Brasília, v.17, n.2, p.86-90, 1999.

STRIK, B.C.; PROCTOR, J.T.A. Estimating the area of trifoliate and uneqully imparipinnate leaves of strawberry. HortScience, Alexandria, v.20, n.6, p.1072-1074, 1985.

SCHIAVUZZO, P.F.; MONTEIRO; F.A.; CARMELLO, Q.A.C.; BANKUTI, A. Determinação do fator de correção para a estimativa da área foliar em braquiária marandu, cultivada em doses de nitrogênio. In: SIMPÓSIO DE INICIAÇÃO CIENTÍFICA DA UNIVERSIDADE DE SÃO PAULO, 1998. São Paulo. Resumos... São Paulo: USP, 1998. v.1, p.498. 